\title{
Effect of Honey and Eugenol on Ehrlich Ascites and Solid Carcinoma
}

\author{
Saravana Kumar Jaganathan, ${ }^{1}$ Dilip Mondhe, ${ }^{2}$ Z. A. Wani, ${ }^{2}$ \\ Harish C. Pal, ${ }^{2}$ and Mahitosh Mandal ${ }^{1}$ \\ ${ }^{1}$ School of Medical Science and Technology, Indian Institute of Technology, Kharagpur 721302, India \\ ${ }^{2}$ Indian Institute of Integrative Medicine, Jammu 180 001, India
}

Correspondence should be addressed to Mahitosh Mandal, mahitosh@smst.iitkgp.ernet.in

Received 4 January 2010; Revised 8 February 2010; Accepted 24 February 2010

Academic Editor: Soldano Ferrone

Copyright ( 2010 Saravana Kumar Jaganathan et al. This is an open access article distributed under the Creative Commons Attribution License, which permits unrestricted use, distribution, and reproduction in any medium, provided the original work is properly cited.

\begin{abstract}
Ehrlich ascites carcinoma is a spontaneous murine mammary adenocarcinoma adapted to ascites form and carried in outbred mice by serial intraperitoneal (i/p) passages. The previous work from our laboratory showed that honey having higher phenolic content was potent in inhibiting colon cancer cell proliferation. In this work, we extended our research to screen the antitumor activity of two selected honey samples and eugenol (one of the phenolic constituents of honey) against murine Ehrlich ascites and solid carcinoma models. Honey containing higher phenolic content was found to significantly inhibit the growth of Ehrlich ascites carcinoma as compared to other samples. When honey containing higher phenolic content was given at $25 \%$ (volume/volume) intraperitoneally (i/p), the maximum tumor growth inhibition was found to be $39.98 \%$. However, honey was found to be less potent in inhibiting the growth of Ehrlich solid carcinoma. On the other hand, eugenol at a dose of $100 \mathrm{mg} / \mathrm{kg}$ i/p was able to inhibit the growth of Ehrlich ascites by $28.88 \%$. In case of solid carcinoma, eugenol $(100 \mathrm{mg} / \mathrm{kg} ; \mathrm{i} / \mathrm{p})$ showed $24.35 \%$ tumor growth inhibition. This work will promote the development of honey and eugenol as promising candidates in cancer chemoprevention.
\end{abstract}

\section{Introduction}

The previous work from our laboratory showed that honey could induce apoptosis in colon cancer cell lines. In the present studies, four honey samples named as Sample A, $\mathrm{B}, \mathrm{C}$, and $\mathrm{D}$ of different origins were investigated for their phenolic content. Among them, Sample C showed higher phenolic content of 65.06 Gallic acid equivalent (GAE), per $100 \mathrm{~g}$ of honey followed by Sample A (60 GAE), Sample D (47.10 GAE) and Sample B (29.96 GAE). The apoptotic potential of honey against colon cancer cells was found to vary among the samples depending upon the phenolic content. Sample C showing higher phenolic content was found to be more potent in inhibiting the cancer cell proliferation as compared to other samples $[1,2]$. In this work, we investigated the antitumor effect of two honey samples (Sample C possessing higher phenolic content and Sample B with lower phenolic content) as well as eugenol (one of the phenolic constituents of honey) against Ehrlich ascites and solid carcinoma.

Ehrlich ascites carcinoma is a spontaneous murine mammary adenocarcinoma [3] adapted to ascites form and carried in outbred mice by serial intraperitoneal (i/p) passages. It has been reported that Ehrlich ascites tumor cells lack H-2 histocompatibility antigens [4], which apparently is the reason for their rapid proliferation in almost any mouse host [5]. Since the description of Ehrlich ascites, researchers exploit it for chemotherapeutic studies. In one recent study, Bhattacharyya et al. [6] studied the apoptogenic effect of black tea against Ehrlich ascites [6]. Moreover effect of antioxidants in development of ascites carcinoma [7] and the role of jacalin in inhibiting the in vivo growth of Ehrlich ascites were also studied [8]. There are various ways to evaluate the antitumor efficacy of any compound against Ehrlich ascites. To mention: (1) examine the ascites cells cytologically after treatment, (2) to measure the increase in 
survival time after using the desired compound of study, and (3) to measure the amount of ascites formed after therapy. For our studies we have used the last mentioned method to evaluate the efficacy of honey samples and eugenol.

Several researchers have investigated the effect of crude honey on cancer. Research conducted on the antitumor activity of honey showed that it possesses moderate antitumor and significant antimetastatic effects in five different kinds of rat and mouse tumors. Moreover, the antitumor activity of certain chemotherapeutic drugs such as 5fluorouracil and cyclophosphamide was facilitated by honey [9]. In vivo studies conducted by Swellam et al. [10] reported that intralesional injection of 6 and 12\% honey as well as oral ingestion of honey significantly inhibited the tumor growth [10]. Eugenol showed significant tumor growth delay, by decreasing the tumor size and inhibiting the tumor metastasis in B16F10 xenograft study [11]. In another research, tumors (papillomas) produced by the application of 7,12-dimethyl benz (a) anthracene as initiator and croton oil as promoter in mice were considerably inhibited by the prior application of eugenol [12].

This work reports the results of antitumor effects of the selected honey samples and eugenol against Ehrlich ascites and solid carcinoma. This work will determine whether the amount of phenolic constituent will have any effect on the antitumor activity of honey against Ehrlich ascites and solid carcinomas.

\section{Materials and Methods}

2.1. Ehrlich Ascites Carcinoma. Ehrlich ascites carcinoma (EAC) cells were collected from the ascitic fluid of BALB/c mice harbouring 8-10 days old ascitic tumor. $1 \times 10^{7}$ EAC cells were injected intraperitoneally in $52 \mathrm{BALB} / \mathrm{c}$ female mice selected for the experiment on day 0 . The next day, animals were randomized and divided into seven groups. Six treatment groups contained 7 animals each and one control group contained 10 animals. Treatment was given as follows:

Group I: Control ( $0.2 \mathrm{~mL}$ of saline; i/p) from day 1 to 9 ,

Group II: $0.2 \mathrm{~mL}$ of $25 \%(\mathrm{v} / \mathrm{v})$ solution of Sample B in normal saline injected consecutively from day 1 to $9(\mathrm{i} / \mathrm{p})$,

Group III: $0.2 \mathrm{~mL}$ of $25 \%$ (v/v) solution of Sample $\mathrm{C}$ in normal saline injected consecutively from day 1 to $9(\mathrm{i} / \mathrm{p})$,

Group IV: Eugenol ( $80 \mathrm{mg} / \mathrm{Kg}$; i/p) injected consecutively from day 1 to 9 ,

Group V: Eugenol (100 mg/Kg; i/p) injected consecutively from day 1 to 9 ,

Group VI: Eugenol (125 mg/Kg; i/p) injected consecutively from day 1 to 9 ,

Group VII: 5-Flurouracil $(20 \mathrm{mg} / \mathrm{Kg}$; i/p) injected consecutively from day 1 to 9 .

The first group administered normal saline $(0.2 \mathrm{~mL}, \mathrm{i} / \mathrm{p})$ from day 1 to 9 was the tumor bearing control; whereas seventh group treated with 5 -fluorouracil served as positive control. On day 12, animals were sacrificed and ascitic fluid was collected from peritoneal cavity of each mouse for the evaluation of tumor growth. Percent tumor growth inhibition was calculated by comparing the total number of tumor cells present in the peritoneal cavity of treated groups and the control group as on day 12 of the experiment. Tumor cell growth in saline-treated control group was taken as 100 percent cell growth.

2.1.1. Preparation and Administration of Doses. For honey samples, $25 \%$ (volume/volume) solutions were prepared in normal saline and $0.2 \mathrm{~mL}$ of these solutions was administered to each mouse intraperitoneally every day at 2.00 PM from days 1 to 9. For Eugenol, its dose (in $\mathrm{mg}$ ) was divided by its specific gravity (1.06) to arrive at its volume to be used in dose preparation. The required volume was emulsified in distilled water by using Tween $80(0.5 \%$ of the total volume). The emulsion was prepared in such a way that the required daily dose was contained in $0.2 \mathrm{~mL}$ of the emulsion. $0.2 \mathrm{~mL}$ of this emulsion was administered to each mouse intraperitoneally, daily at 2.00 PM from day 1 to 9 .

2.2. Ehrlich Tumor (Solid). Ehrlich ascites carcinoma (EAC) cells were collected from the ascitic fluid of BALB/c mice harbouring 8-10 days old ascitic tumor. $1 \times 10^{7}$ EAC cells were injected intramuscularly in right thigh of $38 \mathrm{BALB} / \mathrm{c}$ male mice selected for the experiment on day 0 . The next day, animals were randomized and divided into four groups. Three treatment groups contained 7 animals each and one control group contained 10 animals. Treatment was given as follows:

Group I: Control (normal saline $(0.2 \mathrm{~mL}, \mathrm{i} / \mathrm{p})$ injected consecutively from day 1 to 9 ),

Group II: $0.2 \mathrm{~mL}$ of $50 \%(\mathrm{v} / \mathrm{v})$ solution of Sample C in normal saline injected consecutively from day 1 to $9(\mathrm{i} / \mathrm{p})$,

Group III: Eugenol (100 mg/Kg; i/p) injected consecutively from day 1 to 9 ,

Group IV: 5-Flurouracil $(20 \mathrm{mg} / \mathrm{Kg}$; i/p) injected consecutively from day 1 to 9 .

The first group administered normal saline (NS) $(0.2 \mathrm{~mL}$, $\mathrm{i} / \mathrm{p}$ ) was the tumor bearing control and the fourth group treated with 5-fluorouracil served as positive control. On days 9 and 13, tumor bearing thigh of each animal was shaved and longest and shortest diameters of the tumor were measured with the help of vernier caliper. Tumor weight of each animal was calculated using the following formula:

$$
\text { Tumor weight }(\mathrm{mg})=\frac{\operatorname{Length}(\mathrm{mm}) \times\{\operatorname{width}(\mathrm{mm})\}^{2}}{2} \text {. }
$$

The percent tumor growth inhibition was calculated on day 13 by comparing the average values of treated groups with that of tumor bearing control group. Tumor growth in saline treated control animals was taken to be $100 \%$. 
TABle 1: Body Weights of the Animal after the Treatment.

\begin{tabular}{lccccc}
\hline Treatment & Dose & & \multicolumn{3}{c}{ Body weight $(\mathrm{g})$} \\
Day 9 & Day 5 & 25.62 & 27.00 \\
Control & $0.2 \mathrm{~mL} \mathrm{NS} \mathrm{i/p}$ & 22.75 & 25.37 & 24.57 & 27.28 \\
Sample B & $25 \%(\mathrm{v} / \mathrm{v}) \mathrm{i} / \mathrm{p}$ & 22.71 & 24.57 & 24.83 & 25.33 \\
Sample C & $25 \%(\mathrm{v} / \mathrm{v}) \mathrm{i} / \mathrm{p}$ & 22.85 & 24.66 & 24.66 & 25.91 \\
Eugenol & $80 \mathrm{mg} / \mathrm{kg} \mathrm{i} / \mathrm{p}$ & 22.71 & 23.28 & 24.28 & 25.33 \\
Eugenol & $100 \mathrm{mg} / \mathrm{kg} \mathrm{i} / \mathrm{p}$ & 22.85 & 23.82 & 19.66 & 21.85 \\
Eugenol & $125 \mathrm{mg} / \mathrm{kg} \mathrm{i} / \mathrm{p}$ & 22.57 & 22.57 & 20.42 \\
5-FU & $20 \mathrm{mg} / \mathrm{kg} \mathrm{i} / \mathrm{p}$ & 23.00 & & & Animals died \\
\hline
\end{tabular}

2.2.1. Preparation and Administration of Doses. For honey sample, $50 \%$ (volume/volume) solution was prepared in normal saline and $0.2 \mathrm{~mL}$ of this solution was administered to each mouse intraperitoneally daily at 2.00 PM from days 1 to 9. For Eugenol, its dose (in $\mathrm{mg}$ ) was divided by its specific gravity (1.06) to arrive at its volume to be used in dose preparation. The required volume was emulsified in distilled water by using Twin 80 ( $0.5 \%$ of the total volume). The emulsion was prepared in such a way that the required daily dose was contained in $0.2 \mathrm{~mL}$ of the emulsion. $0.2 \mathrm{~mL}$ of this emulsion was administered to each mouse intraperitoneally, daily at 2.00 PM from day 1 to 9 .

\section{Results}

3.1. Ehrlich Ascites Carcinoma. Body weights of animals were measured regularly on predetermined days. The body weight at the end of day 12 was more compared to the day 1 in all the experimental animals except in case of 5-FU treatment where it showed a decrease. Moreover $125 \mathrm{mg} / \mathrm{kg}$ of eugenol dose was found to be toxic to animals. While comparing the body weight of saline control on day 12 with Sample C and Eugenol treated animals, a decrease in body weights was observed indicating these samples to have effect on the body weights of treated animals (Table 1).

Further more, average volume of ascitic fluid was measured by scarifying all the animals at the end of day 12. Volume collected from the Sample C treated animals (3.41 mL) was found to be less compared to other treatment groups. The number of tumor cells present in the ascitic fluid of each treatment group was also counted. It was observed that Sample C treated animals had only $56.70 \times 10^{7}$ tumor cells as compared to $94.47 \times 10^{7}$ cells in the saline treated control group. Finally, the percent tumor growth inhibition was calculated and it was found to be 12.17 and $39.98 \%$ for Sample B and Sample C, respectively. For eugenol it was observed to be $20.56 \%(80 \mathrm{mg} / \mathrm{kg} \mathrm{i} / \mathrm{p})$ and $28.88 \%$ (100 mg/kg i/p). Eugenol dose of $125 \mathrm{mg} / \mathrm{kg}$ was found to be toxic to the animals (Table 2 ).

3.2. Ehrlich Tumor (Solid). Similar to ascites model, the body weights of animals were measured on predetermined days. The body weights taken on day 12 did not show any decrease in any of the experimental groups as compared to day 1 weights. However, day 12 body weights of animals treated
Sample C and Eugenol were quite lesser as compared to saline treated control indicating these samples to have an effect on the body weights. Further more, average tumor weights calculated on day 12 were found to be considerably less in Eugenol (1412.64 mg) and Sample C (1786.14 mg) treated groups as compared to $1867.35 \mathrm{mg}$ in saline-treated control. The growth inhibition of Ehrlich tumor (solid) was found to be 24.35 and $4.34 \%$ for Eugenol and Sample C treated animals, respectively (Table 3 ).

\section{Discussion}

Epidemiological surveys and experimental studies have provided evidence that environmental factors, including dietary substances, play a major role in the incidence of cancer. Our previous studies reported that the apoptotic potential of honey varied according to the source and phenolic content $[1,2]$. Further more, the molecular mechanism behind the apoptotic potential of honey in vitro was clearly elucidated [13]. Since the apoptotic potential of honey was ascribed to its phenolic constituents, apoptosis inducing mechanism of eugenol, one of the phenolic constituents of honey, was also studied in colon cancer cell lines (unpublished data). In the present studies, we investigated the in vivo effect of honey and eugenol against murine Ehrlich ascites and solid carcinoma models as a preliminary study to initiate our work against immunosuppressive colon cancer in mice models. The choice of honey was made from our previous studies which showed Samples C and B possessing higher and lower phenolic content, respectively. This choice was made to ascertain whether phenolic content has a role in the anticancer activity against Ehrlich ascites and solid carcinoma.

We used 25\% v/v honey solution against Ehrlich ascites carcinoma model. This concentration was chosen arbitrarily and also to overcome the highly viscous nature of honey. Results showed that honey having higher phenolic content (Sample C) inhibited the growth of Ehrlich ascites more effectively as compared to other sample (Sample B). These findings corroborate well with our earlier results obtained in in vitro apoptosis studies conducted on the colon cancer cells where it was observed that the honey containing higher phenolic content was able to inhibit the cancer cell proliferation remarkably as compared to other samples [1]. Mitochondrial and ROS-mediated apoptotic mechanisms 
TABle 2: Percentage of Tumor Inhibition of Ehrlich Ascites after Treatment.

\begin{tabular}{|c|c|c|c|c|c|c|c|}
\hline \multirow{2}{*}{ Treatment } & \multirow{2}{*}{ Dose } & \multicolumn{6}{|c|}{ Day 12} \\
\hline & & $\begin{array}{l}\text { Avg. volume of } \\
\text { ascitic fluid } \\
(\mathrm{mL})\end{array}$ & $\begin{array}{l}\text { Avg. weight of } \\
\text { ascitic fluid (g) }\end{array}$ & $\begin{array}{c}\text { Avg. No. of } \\
\text { tumor cells } \\
\times 10^{7} \\
\end{array}$ & $\begin{array}{l}\text { \% Tumor cell } \\
\text { growth }\end{array}$ & $\begin{array}{l}\% \text { Tumor } \\
\text { growth } \\
\text { inhibition }\end{array}$ & Mortality \\
\hline Control & $0.2 \mathrm{~mL} \mathrm{NS} \mathrm{i/p}$ & 7.64 & 8.16 & 94.47 & 100.00 & 00.00 & $0 / 10$ \\
\hline Sample B & $25 \%(\mathrm{v} / \mathrm{v}) \mathrm{i} / \mathrm{p}$ & 7.01 & 7.33 & 82.97 & 87.83 & 12.17 & $0 / 7$ \\
\hline Sample C & $25 \%(\mathrm{v} / \mathrm{v}) \mathrm{i} / \mathrm{p}$ & 3.41 & 3.66 & 56.70 & 60.02 & 39.98 & $0 / 7$ \\
\hline Eugenol & $80 \mathrm{mg} / \mathrm{kg} \mathrm{i} / \mathrm{p}$ & 7.02 & 7.46 & 84.09 & 79.44 & 20.56 & $0 / 7$ \\
\hline Eugenol & $100 \mathrm{mg} / \mathrm{kg} \mathrm{i} / \mathrm{p}$ & 9.88 & 9.86 & 75.28 & 71.12 & 28.88 & $0 / 7$ \\
\hline Eugenol & $125 \mathrm{mg} / \mathrm{kg} \mathrm{i} / \mathrm{p}$ & \multicolumn{3}{|c|}{ All animals died by 10th day } & & Intolerable & $7 / 7$ \\
\hline 5-FU & $20 \mathrm{mg} / \mathrm{Kg} \mathrm{i} / \mathrm{p}$ & 0.40 & 0.38 & 05.23 & 05.54 & 94.46 & $0 / 7$ \\
\hline
\end{tabular}

TABle 3: Average Weights and Tumor Inhibition of Ehrlich Solid Tumor after Treatment.

\begin{tabular}{|c|c|c|c|c|c|c|c|}
\hline \multirow{2}{*}{$\begin{array}{l}\text { Treatment } \\
\text { Groups }\end{array}$} & \multicolumn{3}{|c|}{ Avg. Body weights ( $\mathrm{g}$ ) of animals on days } & \multicolumn{2}{|c|}{ Day 13} & \multirow{2}{*}{$\begin{array}{l}\text { \%Tumor } \\
\text { growth } \\
\text { inhibition }\end{array}$} & \multirow{2}{*}{ Mortality } \\
\hline & 1 & 5 & 9 & $\begin{array}{c}\text { Avg. body } \\
\text { weights (g) }\end{array}$ & $\begin{array}{l}\text { Avg. tumor weights } \\
\qquad(\mathrm{mg})\end{array}$ & & \\
\hline $\begin{array}{l}\text { Eugenol } \\
(100 \mathrm{mg} / \mathrm{kg} \mathrm{i} / \mathrm{p})\end{array}$ & 19.57 & 21.0 & 19.71 & 20.57 & 1412.64 & 24.35 & $0 / 7$ \\
\hline $\begin{array}{l}\text { Sample C (50\% } \\
\text { v/v i/p) }\end{array}$ & 19.85 & 20.71 & 20.71 & 21.57 & 1786.14 & 4.34 & $0 / 7$ \\
\hline $\begin{array}{l}\text { Positive control } \\
5 \mathrm{FU}(22 \mathrm{mg} / \mathrm{kg} \\
\mathrm{i} / \mathrm{p})\end{array}$ & 21.14 & 21.71 & 21.16 & 21.33 & 1275.5 & 31.69 & $0 / 7$ \\
\hline $\begin{array}{l}\text { Normal Control } \\
\text { NS }(0.2 \mathrm{~mL} \mathrm{i} / \mathrm{p})\end{array}$ & 21.25 & 22.71 & 22.42 & 22.71 & 1867.35 & - & $0 / 10$ \\
\hline
\end{tabular}

observed in the antiproliferative activity of honey might have a putative role in the antitumor activity of honey against Ehrlich ascites [13]. The antitumor effect of honey observed in the present investigation was similar to the effect of some other natural products like black tea and jacalin against Ehrlich ascites reported previously $[6,8]$. Ehrlich solid carcinoma bearing animals were treated with increased concentration of honey $(50 \% \mathrm{v} / \mathrm{v})$ since these animals were found to be more resistant to treatment with honey as compared to ascites bearing animals. Results demonstrated that even at such a higher concentration of honey, it could not show any drastic change in the growth of Ehrlich solid carcinoma. The antitumor efficacy against solid carcinoma was only $4.34 \%$ compared to $39.98 \%$ against ascites carcinoma. This inefficacy of honey may be due to the systemic effect necessitated by the solid carcinoma.

In case of Eugenol, we had chosen three arbitrary concentrations of 80,100 , and $125 \mathrm{mg} / \mathrm{kg}$ based on the recent anticancer work done against melanoma [11]. In our studies, a dose of $125 \mathrm{mg} / \mathrm{kg}$ proved toxic to animals. A dose of $100 \mathrm{mg} / \mathrm{kg}$ was found to be potent against Ehrlich ascites with an antitumor efficacy of $29 \%$ approximately. Hence we used the same concentration $(100 \mathrm{mg} / \mathrm{kg})$ against Ehrlich solid tumor. Although efficacy against Ehrlich solid tumor was less for honey, eugenol showed a fairly good inhibition in the growth of solid tumor (antitumor efficacy of $24.35 \%$ ). The observed antitumor effect was analogous with the previous report on its antitumor activity against B16F10 xenograft study [11] and in tumors (papillomas) produced by the application of 7, 12-dimethyl benz (a) anthracene as initiator [12].

Our studies confirmed that the honey with higher phenolic content inhibits the growth of Ehrlich ascites more effectively. Hence antitumor effect against Ehrlich ascites could be attributed to its phenolic content and its antioxidant ability, since Sample C showed significant effect as compared to Sample B. In case of solid Ehrlich tumor honey was found to be less potent. This may occur because of more resistant nature of Ehrlich tumor (solid) and its inhibition requiring systemic effect. Eugenol had shown remarkable inhibition of both Ehrlich ascites and solid tumor. We surmise that mitochondrial and ROS-mediated apoptotic mechanism observed in the antiproliferative activity of honey might have a role in this antitumor activity [13]. To explain further, it is essential to study the exact molecular mechanism behind the antitumor activity of honey and eugenol against Ehrlich tumor.

\section{Acknowledgments}

Jaganathan acknowledges I.I.T Kharagpur for his research fellowship for doing this study. All authors acknowledge Ms. Bhuvaneswari S. for formatting and checking this paper. 


\section{References}

[1] S. K. Jaganathan and M. Mandal, "Honey constituents and its apoptotic effect in colon cancer cells," Journal of ApiProduct and ApiMedical Science, vol. 1, pp. 29-36, 2009.

[2] S. K. Jaganathan, S. M. Mandal, S. K. Jana, S. Das, and M. Mandal, "Studies on the phenolic profiling, anti-oxidant and cytotoxic activity of Indian honey: in-vitro evaluation," Natural Products Research. In press.

[3] P. Ehrlich and H. Apolant, "Beobachtungen uber maligne mausentumoren," Berlin Klin Wochenschr, vol. 42, pp. 871874, 1905.

[4] L. Chen and J. F. Watkins, "Evidence against the presence of $\mathrm{H}_{2}$ histocompatibility antigens in Ehrlich ascites tumour cells," Nature, vol. 225, no. 5234, pp. 734-735, 1970.

[5] H. M. Patt and R. L. Straube, "Measurement and nature of ascites tumor growth," Annals of the New York Academy of Sciences, vol. 63, no. 5, pp. 728-737, 1956.

[6] A. Bhattacharyya, T. Choudhuri, S. Pal, et al., "Apoptogenic effects of black tea on Ehrlich's ascites carcinoma cell," Carcinogenesis, vol. 24, no. 1, pp. 75-80, 2003.

[7] W. A. Baumgartner, V. A. Hill, and E. T. Wright, "Antioxidant effects in the development of Ehrlich ascites carcinoma," American Journal of Clinical Nutrition, vol. 31, no. 3, pp. 457465, 1978.

[8] H. Ahmed, B. P. Chatterjee, and A. K. Debnath, "Interaction and in vivo growth inhibition of Ehrlich ascites tumor cells by jacalin," Journal of Biosciences, vol. 13, no. 4, pp. 419-424, 1998.

[9] N. V. Gribel and V. G. Pashinskiì, "The antitumor properties of honey," Voprosy Onkologii, vol. 36, no. 6, pp. 704-709, 1990.

[10] T. Swellam, N. Miyanaga, M. Onozawa, et al., "Antineoplastic activity of honey in an experimental bladder cancer implantation model: in vivo and in vitro studies," International Journal of Urology, vol. 10, no. 4, pp. 213-219, 2003.

[11] R. Ghosh, N. Nadiminty, J. E. Fitzpatrick, W. L. Alworth, T. J. Slaga, and A. P. Kumar, "Eugenol causes melanoma growth suppression through inhibition of E2F1 transcriptional activity," Journal of Biological Chemistry, vol. 280, no. 7, pp. 58125819, 2005.

[12] K. Sukumaran, M. C. Unnikrishnan, and R. Kuttan, "Inhibition of tumour promotion in mice by eugenol," Indian Journal of Physiology and Pharmacology, vol. 38, no. 4, pp. 306-308, 1994.

[13] S. K. Jaganathan and M. Mandal, "Involvement of non-protein thiols, mitochondrial dysfunction, reactive oxygen species and p53 in honey-induced apoptosis," Investigational New Drugs. In press. 


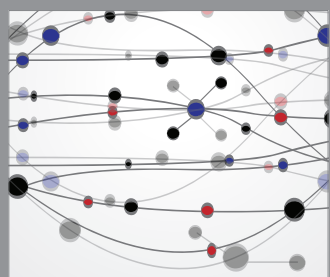

The Scientific World Journal
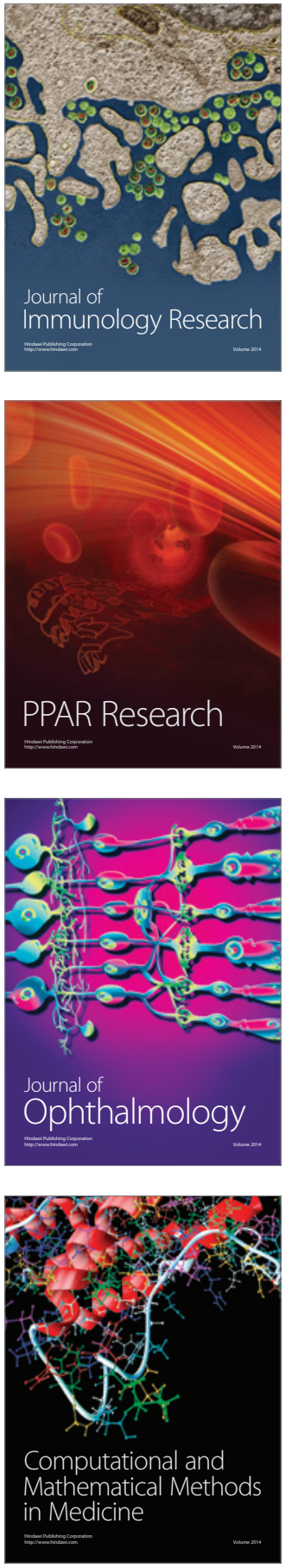

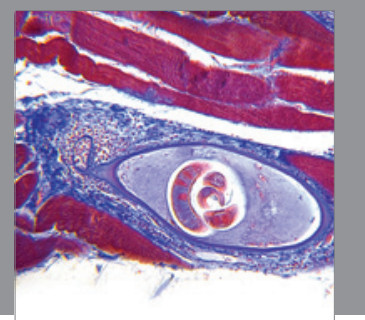

Gastroenterology

Research and Practice
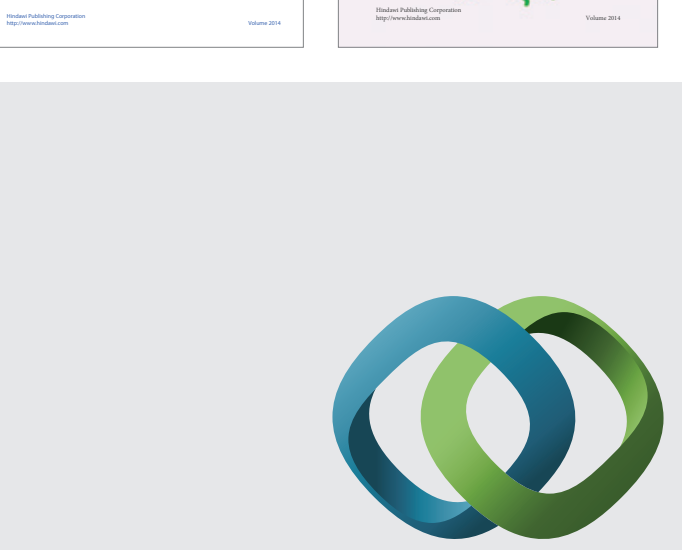

\section{Hindawi}

Submit your manuscripts at

http://www.hindawi.com
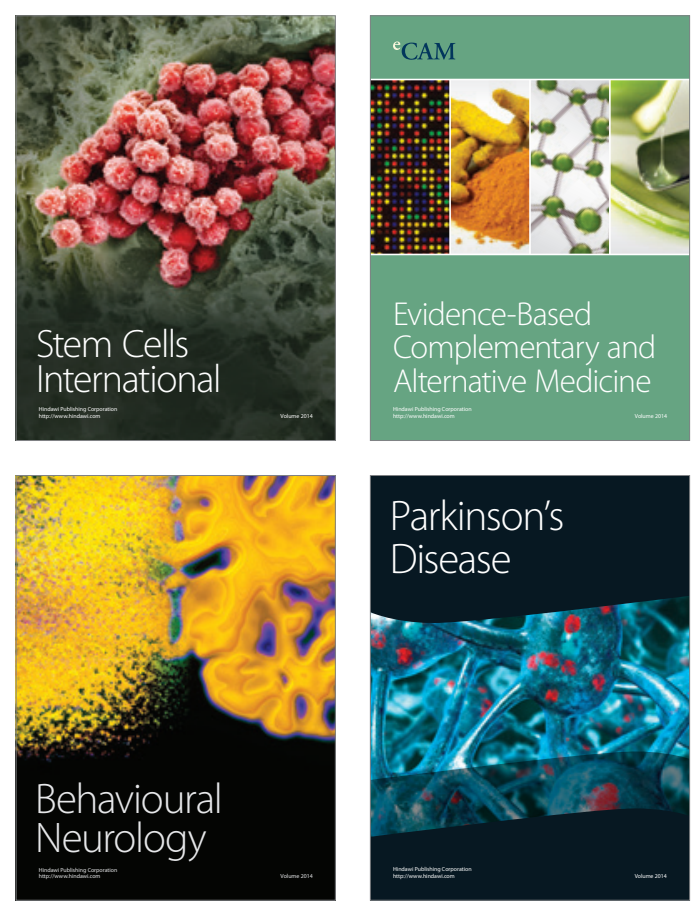

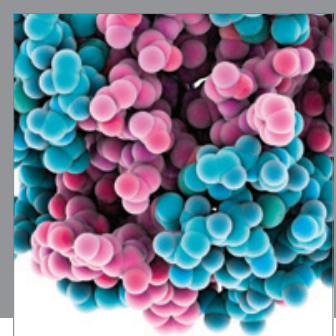

Journal of
Diabetes Research

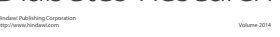

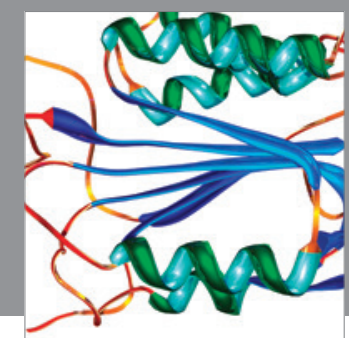

Disease Markers
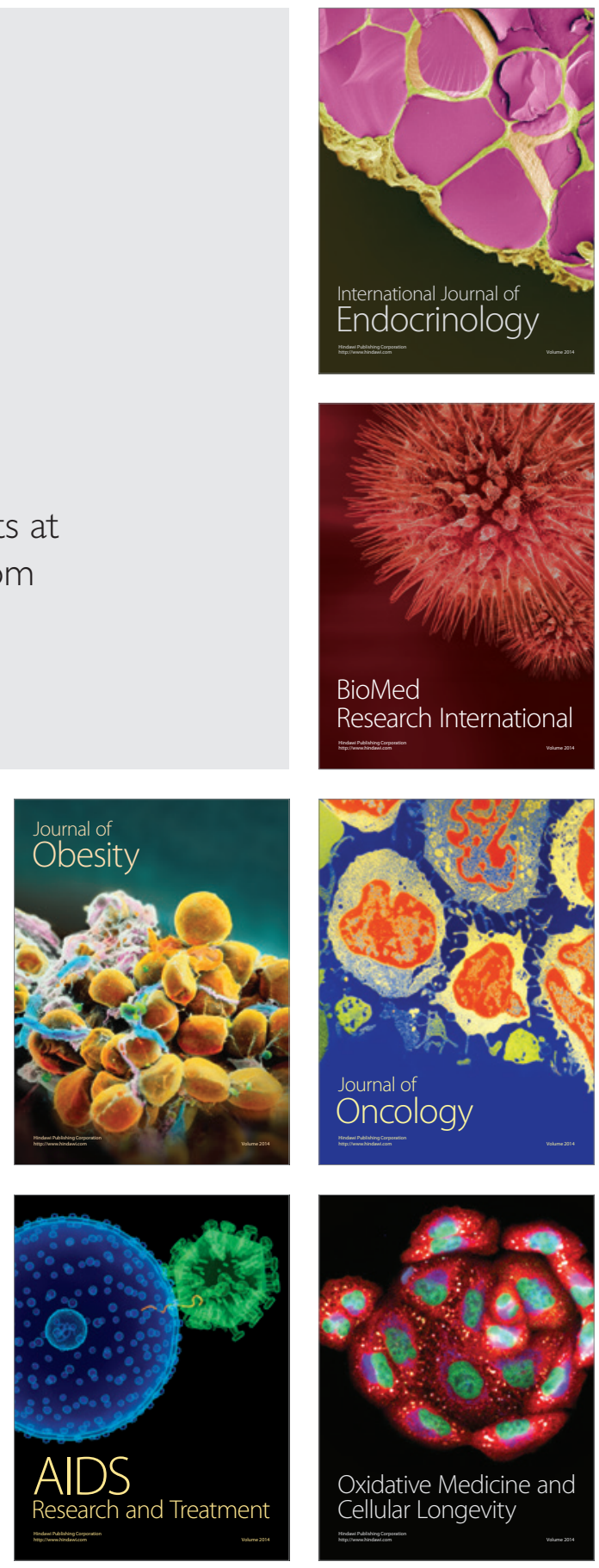